\title{
ESTADO DE LA CUESTIÓN SOBRE EL POBLAMIENTO DURANTE EL CALCOLITICO Y LA EDAD DEL BRONCE EN LAS SUBBETICAS CORDOBESAS
}

\author{
Juan F. MURILLO REDONDO (*)
}

\section{Introducción}

Las Subbéticas cordobesas han alcanzado justo renombre en la bibliografía prehistórica andaluza merced a yacimientos que, como la cueva de los Murciélagos de Zuheros (MUÑOZ-VICENT, 1969) y ta de Los Mármoles (ASQUERINO, 1987), han aportado datos del máximo interés para el conocimiento del Neolítico andaluz. Sin embargo, lo que podríamos denominar Prehistoria Reciente (Calcolítico y Edad del Bronce) se presenta como una etapa mal deñnida, con apenas algunos materiales aparecidos fuera de contexto y de cronología imprecisa (LÓPEZ PALOMO, 1977; GAVILÁN, 1987). Este hecho contrasta con la situación de las inmediatas Campiñas de Córdoba y Jaén, donde una serie de trabajos recientes (RUIZ LARA, 1988; CARRILERO et alii, 1982; CARRILEROMARTÍNEZ, 1985; RUIZ et alii, 1986; NOCETE, 1989) están poniendo de reüeve un intenso poblamiento correspondiente a estos momentos.

En este trabajo nos proponemos abordar el estudiode la ocupación durante el Calcolítico y la Edad del Bronce en las Subbéticas cordobesas como marco introductorio al análisis del poblamiento protohistórico y antiguo de la zona. Para ello nos basaremos tanto en los resultados de las dos primeras campañas de prospecciones superficiales, realizadas en los años 1986 y 1989 dentro del proyecto "Protohistoria y Romanización en las Subbéticas cordobesas" (VAQUERIZO, 1990), como en los materiales conservados en colecciones públicas y particulares, algunos de ellos ya publicados (ASQUERINO, 1985; GAVILÁN, 1987; RUIZ LARA, 1987; MURILLO-RUIZ LARA, 1990). Somos conscientes de que las próximas campañas de prospección pueden modificar algunos de los planteamientos aquí adoptados, aunque creemos que los nuevos datos no afectarán de modo sustancial a la estructuración de la red primaria de poblamiento que postulamos.

Será preciso esperar a la obtención de secuencias estratigrafías para tener una visión más precisa de la dinámica de estas poblaciones de las Edades de los Metales, así como a excavaciones en extensión de los asentamientos para entrever los principales aspectos de su cultura material y de su organización económica y social. A este respecto sería del máximo

(*) Área de arqueología. De partamento de Ciencias de la Antigüedad. Universidad de Córdoba. 
interés conocer las áreas de deposición funeraria, hasta ahora sólo documentadas de forma parcial para la Edad del Bronce.

\section{Los yacimientos}

2.1.1. La Mesa (Fuente Tójar). Amplia meseta al Oeste del casco urbano. Sobre una gran superficie aparece numeroso material cerámico y lítico, parte del cual se conserva en el Museo Local de Fuente Tójar. La ocupación del poblado parece iniciarse en el Neolítico Final, al que corresponderían varios fragmentos de cerámicas decoradas a la almagra y con pintura rojiza sobre engobe crema, similares estas últimas a las de la Cueva de Los Mármoles (ASQUERINO, 1985) y a las de varios yacimientos de la Campiña del Guadajoz (CARRILERO-MARTÍNEZ, 1985; RUIZ LARA, 1988). Más definitorios del Neolítico andaluz resultan los fragmentos de brazaletes de mármol, con paralelos en numerosos yacimientos de la "Cultura de las Cuevas" (NAVARRETE, 1976; ACOSTA, 1986).

El Neolítico Final-Calcolítico Inicial muestra varios fragmentos de fuentes carenadas (Fig. 3, núms. 1 y 2), en tanto que el Pleno está bien representado por gran número de platos y fuentes de borde engrosado, con una variada tipología que abarca desde los de labio simple a los almendrados. No tenemos noticias de hallazgos de cerámica campaniforme en La Mesa, aunque sí de otros ítems que suelen ser típicos del Calcolítico Final, como los denominados "brazaletes de arquero" y algunas puntas de Pal mella localizadas en la ladera meridional de La Mesa, en dirección al Carmelo. También son característicos de estos momentos, equiparables al Horizonte Cazalilla II- Albalate de laCampiña de Jaén, los platos de borde biselado (Fig. 4, núm. 1), presentes en el Cobre Reciente de Montefrío (ARRIBASMOLINA, 1978). Cuencos hemiesféricos, vasos globulares y de perfil en $S$ con cuello indicado, así como "cuernecillos" y una variada industria Iftica con hojas retocadas y sin retocar, muchas de ellas con pátina de siega, perforadores y alguna punta de flecha de base cóncava, completan el panorama ergológico del Caicolítico de La Mesa.

Varios vasos de superficies bruñidas y carenas medias (Fig. 3, núms. 3 y 9) podrían corresponder a los inicios de la Edad del Bronce, aunque también podemos documentar formas similares en contextos calcolíticos. Más signiñcativos resultan en cambio ios cuencos parabólicos (Fig. 3, núm. 7), los vasos parabólicos de borde entrante (Figs. 3, núm. 8 y 2 , núm. 12) y los vasos con una acusada carena en su parte inferior.

MARTÍNEZ SANTA-OLALLA (1935) tuvo ocasión, en el curso de sus trabajos arqueológicos en el Cerro de la Cruz, Cerro de las Cabezas y Cueva de los Mármoles, de conocer materiales procedentes de La Mesa. Así, cita la existencia de "mucha cerámica lisa, con frecuencia de superficie grosera y bordes fuertemente perfilados". Junto a ellos, una importante industria lítica, con lascas, hojas, raspadores, buriles, trapecios, puntas de flecha "de base cóncava" y "finísimo trabajo", dientes de,hoz, molinos de mano, machacadores... Como se advierte, se trata de un horizonte muy similar al que presentan los materiales a que hemos tenido acceso.

2.1.2. Fuente Tójar. Como procedente de esta localidad se conservan en el Museo Arqueológico Nacional varias piezas metálicas. De entre ellas sobresale una "espada" (Fig. 6) de $364 \mathrm{~mm}$. de longitud por 79 de anchura máxima. La placa de enmangue se encuentra muy deteriorada, por lo que es difícil precisar la forma de su base y el número de remaches, que parecen haber sido tres y dispuestos en triángulo, con el superior sobre el 
grueso nervio central que recorre la hoja en toda su longitud y los restantes uno a cada lado del mismo. Los filos se encuentran muy deteriorados y mellados. Aunque la única referencia sobre su procedencia es Fuente Tójar, creemos que el único yacimiento del que puede proceder es La Mesa, tan próximo al actual pueblo que explica la identificación.

La primera noticia que conocemos sobre esta pieza se debe a PERICOT (1942:218), quien se limita a publicar una fotografía. Pocos años después seria de nuevo publicada por CARRIAZO (1947:782; Fig. 599), que habla de un "hallazgo suelto" efectuado en Fuente Tójar y que, junto a la "'espada", incluiría cinco hachas planas, un cuchillo y una punta de flecha con pedúnculo, todo ello de cobre. Debido a la presencia del nervio central en ambas caras, resalta su singularidad respecto a las espadas argáricas, señalando su carácter más evolucionado, que la situaría, según este investigador, en la ' 'transición a las espadas de la Segunda Edad del Bronce" (= Bronce Final).

Años después sería incluida en el corpus de BLANCE (1971:188) quien, aparte de creerla inédica, la incluye en su tipo IV de los puñales-espadas argáricos, caracterizados por una longitud de más de $305 \mathrm{~mm}$. y considerados auténticas espadas. Esta investigadora también pudo estudiar en el M.A.N. dos de las hachas citadas por CARRIAZO como procedentes del mismo hallazgo, clasificando una en su Tipo I de hachas argáricas (BLANCE, 1971:189) y la otra dentro de las hachas de tipo trapezoidal (BLANCE, 1971: 199). ALMAGRO GORBEA (1972 y 1976) no la recoge en sus trabajos sobre las espadas peninsulares de la Edad del Bronce, y sólo recientemente CARRASCO y PACHÓN (1986: 365) han vuelto a tratarla en relación con las "alabardas" o "espadas cortas" de Cerro Benzalá (CARRASCO-PACHÓN, 1986: Fig. 9) y de El Laderón (BERNIER et alii, 1981: 105-106; Lám. LIV), fechándola en el Bronce Final.

Lo expuesto hasta ahora sirve como botón de muestra de las dificultades que plantea el mero análisis tipológico de piezas de este tipo halladas fuera de contexto. Esto se traduce no sólo en la asignación de cronología -desde el Argar B al Bronce Final-, sino también en la propia definición del tipo de arma -espada, espada corta, puñal largo, alabarda-. Es por ello por lo que deberemos comenzar por saber de qué estamos hablando para luego establecer su marco cultural y cronológico.

Los únicos intentos serios de análisis tipológico del armamento y utillaje metálicos argáricos se deben a LULL (1983), quien emplea criterios morfométricos, morfológicos y funcionales exhaustivos que suponen un notable avance en relación con los meramente subjetivos usados con anterioridad (BLANCE, 1971; SCHUBART, 1973 y 1975). De acuerdo con su metodología, hemos comenzado por la primera posibilidad, considerarla una alabarda de gran tamaño. El único rasgo morfológico que en principio haría viable esta hipótesis sería la posesión del grueso nervio central, privativo de las alabardas y ausente de la práctica totalidad de espadas de la Edad del Bronce. La longidad $(364 \mathrm{~mm}$.) es la primera nota discrepante, por cuanto la mayor de las alabardas estudiadas por LULL, la de Montejícar, no pasa de los $280 \mathrm{~mm}$. Sin embargo, esto no es decisivo para excluir la posibilidad de que se trate de una alabarda, pues una portuguesa de tipo Garrapatas procedente de Alto de Pereira, en Tras os Montes (SCHUBART, 1973: Fig. 7), tiene una longitud algo superior a los $300 \mathrm{~mm}$.

Por su anchura (79 mm.), la pieza de Fuente Tójar entraría en el grupo de las de base ancha, junto a la alabarda de Peñalosa y a varias más de El Algar y Deifontes (LULL, 1983b). Los índices de proporción y de concavidad (0,21 y 0,20 respectivamente) la colocarían entre las alabardas muy largas y estrechas y con mínima o nula concavidad, junto 
a los ejemplares de Peñalosa, Montejícar, Arrayanes y Argar 575. Si atendemos a la relación LA, la pieza está muy alejada del grupo argárico, así como del constituido por los ejemplares de Montejícar, Argar 575 y Peñalosa, aquellos con los que hasta ahora había mantenido mayores semejanzas y que singularizarían los dos tipos restantes de alabardas argíricas (tipos Montejícar y Carrapatas) tal como los definiera SCHÜBART (1973). En consecuencia, o nos encontramos ante un nuevo tipo de alabarda, que vendría deñnida por su gran tamaño más que por cualquier otro rasgo morfológico o métrico, lo que nos parece muy improbable, o debemos buscar en otra dirección su caracterización tipológica.

De acuerdo con los criterios de LULL (1983) nuestro ejemplar debería incluirse en un grupo intermedio, el de todas las piezas que no poseen los rasgos señalados para cuchillospuñales y espadas. Son todas ellas excepcionales desde el punto de vista morfométrico, lo que impide establecer subtipos. Sus variables serían: Longitud entre 20 y $50 \mathrm{cms}$.; Anchura entre 2,4 y 7,5 cms.; Número de remaches aleatorio, de 2 a 7.

Como vemos, todas ellas se ajustan al ejemplar de Fuente Tójar, que encuentra la mayor proximidad morfométrica en los grandes puñales de Zalabí A y C, Fuente Álamo I y Argar 994, y en el ejemplar B de Montefrío, a caballo entre los grandes puñales-estoques y las espadas (LULL, 1983). Pese a todo, las diferencias son muy amplias, tanto en la forma de la placa de enmangue, como en el grueso nervio central que recorre la hoja, ausente en la totalidad de puñales y espadas argárícas y que comparten la pieza de Fuente Tójary un puñal de la cueva prieguense de Huerta Anguita (vid. infra). Sólo la espada lucense de Forcas, clasificada por ALMAGRO GORBEA (1972: Fig. 4) en su tipo He, presenta una acusada arista central en la hoja, además de una forma estrecha y filos rebajados, característica esta última compartida por los ejemplares de Montejícar y Montefrío. AUBET-SERN A (1981) señalan cómo estos rasgos suponen un avance técnico en relación con las demás espadas peninsulares que denotaría la influencia de los denominados estoques atlánticos de enmangue trapezoidal, lo que dataría a este grupo en tomo al 1200-900 a.C.

Un fuerte engrosamiento de la hoja, aunque sin constituir un nervio, se presenta también en el estoque de Mesa de Se te filia, pieza singular sin paralelos en la Península Ibérica. Tampoco guarda relación con los estoques conocidos en el Mediterráneo Oriental, pero sí con los de la Europa Centro-Occidental, en especial con los ingleses más antiguos. Sin embargo, tanto las diferencias en el sistema de enmangue como la alta cronología proporcionada por C-14 del nivel que contenía la sepultura en que apareció, $1570+95$ a.C, abogan por su consideración como arma de fabricación local muy anterior al apogeo y máximo desarrollo de los estoques europeos, en tomo al 1300-1200 (AUBET-SERNA, 1981:239).

El paralelo más claro para la hoja de daga de Fuente Tójar lo hallamos en la pieza de Torre Benzalá (CARRASCO-PACHÓN, 1986: Lám. IV), si bien ésta difiere en la posesión de una fuerte lengüeta de enmangue de forma trapezoidal. Con todo, esta diferencia debe ser relativizada, pues no debemos olvidar que en el ejemplar cordobés la zona de enmangue se encuentra muy deteriorada, no siendo arriesgado suponer la posesión de una pequeña lengüeta en la que se alojaría el remache superior, con un aspecto muy similar al que presenta la base de la alabarda de Peñalosa (SCHÜBART, 1973: Fig. 7b).

El problema se plantea de nuevo al definir a qué tipo de arma responde la pieza de Torre Benzalá: alabarda o daga. La aplicación de los criterios morfométricos de LULL arroja resultados similares a los obtenidos para el ejemplar de Fuente Tójar, razón por la que creemos encontrarnos también en este caso ante una daga o puñal largo. 
Para la cronología de estas piezas no contamos con pautas claras por proceder ambas de hallazgos fuera de contexto. En principio no consideramos concluyente la datación de la de Torre Benzalá en el Bronce Final pues se basa en la presencia de cerámicas de esta etapa en la superficie del yacimiento en que se halló, y en su comparación con la daga de Fuente Tójar. Por la misma razón, la de Fuente Tójar podría datarse tanto en el Bronce Pleno como en el Bronce Final, ambos presentes en el complejo arqueológico La Mesa-Cerro de las Cabezas. Fs más, si las hachas planas y la punta de flecha con pedúnculo formaban parte, jumo a la daga, de un depósito, una cronología del Bronce Pleno sería la más plausible.

Mayor precisión podría aportar la noticia proporcionada por CARRASCO y PACHÓN (1986) sobre un arma similar a la de Torre Benzalá en el Cortijo de las Torres (Mengíbar), al parecer procedente de una tumba de incineración. Este hecho, de confirmarse, abogaría por una cronología reciente, si bien por ahora nos mostramos cautos dadas las circunstancias que rodearon el descubrimiento de estas supuestas incineraciones en urna (CARRASCO $e t$ alii) 980). Por otro lado, no debemos olvidar que otra pieza estrechamente relacionada con las que aquí nos ocupan, la alabarda o daga de El Laderón (BERNIER et alii, 1981), fue hallada en el interior de una cista, en un contexto que encajaría bien en un Bronce Pleno y formando parte del ajuar de un enterramiento que ofrece un ritual funerario muy diferente al del Cortijo de las Torres. Por desgracia, de nuevo las circunstancias que rodearon el hallazgo de El Laderón y el carácter semiinédito de los materiales impiden obtener conclusiones más precisas.

Una línea diferente, aunque a nivel de hipótesis, es la que ofrece la comparación de este grupo de armas con las alabardas tipo Montejícar. En efecto, al realizar el análisis morfométrico de LULL hemos podido comprobar cómo los ejemplares de Fuente Tójar y de Torre Benzalá se hallaban muy próximos a la alabarda de Montejícar y a la Argar 575, considerada esta última como una hoja de alabarda argáríca que imita el modelo de aquella (LULL, 1983b). Hemos incluido en el análisis las alabardas de Ecija, Campiña y Monte do Castelo, no consideradas por LULL por hallarse fuera del área argárica, pero que SCHÜBART(1973)clasifica dentro del tipo Montejícar, comprobando que todas forman un grupo bastante homogéneo, con bajos índices de concavidad y de relación anchura/longitud.

Si bien en el caso de las piezas que aquí nos ocupa no nos encontramos con alabardas, sino con dagas o puñales largos, debemos llamar la atención sobre la gruesa lengüeta trapezoidal que sirve de enmangue al ejemplar de Torre Benzalá y compararlo con las placas de enmangue de las alabardas tipo Montejícar, y muy en especial con las de Monte do Castelo y Campiña (SCHÜBART, 1973: Figs. 1Od y 1 la). Aunque las diferencias morfológicas son patentes, creemos que el rasgo esencial, la lengüeta o placa rectangular o trapezoidal es común a ambos tipos de armas, SCHÜB AR (1973:260-262) considera que las alabardas del Argar A son la trasposición del puñal con remache, encontrándose con la dificultad de derivar las de Tipo Montejícar tanto de las alabardas argáricas, al faltar tipos intermedios, como de puñales con lengüeta, no documentados por aquel entonces en la Península. Ante esta doble evidencia negativa, acabará optando por una influencia de modelos mediterráneoorientales.

Las dagas de Fuente Tójar y de Torre Benzalá podrían haber servido de punto de partida para estas alabardas, siempre que se acepte la dependencia de la alabarda respecto al puñal. Los estudios de LULL sobre la alabarda argárica, con la definición de un proceso de evolución técnica y cronológica del arma, patente en la búsqueda de las proporciones óptimas que asegurasen la mayor eficacia con el mínimo gasto de materia prima (LULL, 
1983b: 201), pueden considerarse indicativos a este respecto.

Queda por valorar la significación cultural de estos conjuntos de armas. El primer punto de interés es que todas se encuentren en la periferia del área de expansión de la cultura argárica o en el ámbito de la cultura del Bronce del Suroeste, para la que se admiten relaciones con aquélla (SCHÜBART, 1975). En segundo lugar, las manifiestas diferencias con los tipos argáricos impide considerarlas como originarias de ese foco metalúrgico. En consecuencia, es factible considerar la existencia de un foco metalúrgico que comercializó sus productos por toda la Cuenca del Guadalquivir y áreas limítrofes. El estoque de Setefílla sería buena prueba de la dinamicidad de este centro metalúrgico, que ya hacia mediados del n milenio había creado sus propios prototipos (AUBET-SERNA, 1981) y que es posible que tuviera su razón de ser en los depósitos mineros de Sierra Morena. Las relaciones, más o menos directas, con la cultura argárica vendrían dadas por las alabardas de Peñalosa y de Mesa de Setefilla, ambas tipos híbridos que reúnen rasgos argáricos -en especial la de Setefílla, que morfométricamente es una perfecta alabarda argárica del tipo II de LULL- con otros (lengüeta y doble o triple nervio en la hoja) que cabría considerar típicos del foco metalúrgico occidental.

2.1.3. ElCañuelo (Priego de Córdoba). De ¡as proximidades de esta aldea de Priego de Córdoba, a poca distancia al Suroeste de La Mesa de Fuente Tójar, procede un hacha plana con rebordes (GAVILÁN 1987: 99) conservada en el Museo Local de Fuente Tójar. La valoración de este hallazgo, encuadrable en un momento impreciso de la Edad del Bronce, debe hacerse en función de su proximidad a La Mesa.

2.1.4. El Esparragal (Priego de Córdoba). Con este topónimo se conoce un cerro de abruptas laderas, estratégicamente ubicado frente a la confluencia de ios ríos Salado y Zagrilla y con una torre vigía medieval en su cima. Del asentamiento prehistórico que debió existir aquí dan testimonio los siguientes materiales, unos publicados por GAVILAN (1987) y otros recogidos por nosotros en prospección superficial:

- Varios fragmentos de bordes pertenecientes a vasos hemiesféricos y globulares, platos de borde engrosado (v. gr. GAVILÁN, 1987: Fig. 53,1) y fuentes carenadas (Fig. 4, núm. 5).

- Varios fragmentos atípicos de cerámica decorada (incisa y almagra).

- Fragmento de brazalete de calcita, ancho y liso.

- Industria lítica integrada por una arista retocada, con pátina de siega, y por fragmentos de hojas y de lascas sin retocar, así como por restos de talla. Cincel de piedra pulimentada (GAVILÁN, 1987: Fig. 53,4).

El cuadro cronológico que se desprende de estos hallazgos es el de un yacimiento con una ocupación inicial en el tránsito del Neolítico Final al Calcolítico Inicial (fuentes carenadas, brazalete de calcita, cerámicas incisas y a la almagra), que perduraría durante al menos todo el Cobre (bordes engrosados). Por ahora, sólo unos fragmentos atípicos de cerámica bruñida y alguna carena permiten contemplar la posibilidad de ocupación durante la Edad del Bronce.

2.1.5. Cueva de la Detrito (Priego de Córdoba). Se abre en la ladera occidental del Cerro de El Esparragal. De aquí procede un lote de materiales publicado por GAVILÁN (1987: Fig. 53, núms. 1 y 2) e integrado por: 
- Fragmento perteneciente a un plato de borde engrosado.

- Atípico de cerámica a la almagra.

- Hoja con escotadura, raspador, resto de núcleo y restos de talla.

A estos vestigios arqueológicos debemos unir una serie de restos óseos humanos, al parecer de un único individuo, y varios objetos pertenecientes a un ajuar funerario (GAVILÁN-MORENO, 1987):

- Dos vasos con cuerpo globular y cuello desarrollado, uno de ellos con pequeños mamelones redondeados; superficies bruñidas.

- Un puñal triangular, cono, con filos rebajados y siete muescas en la base.

- "Espada" con filos rebajados, base semicircular y cuatro remaches en arco. De acuerdo con los criterios morfométricos de LULL (1983), esta pieza debe ser considerada un puñal largo o daga.

- Raspador sobre hoja de sílex y resto de núcleo.

- Cáscara de almendra recubierta de ocre rojo.

- Fragmento de grafito.

Todos los indicios apuntan a que nos encontramos ante una cuevanatural utilizada como área de enterramiento por las gentes del poblado de El Esparragal, con el que forma un único conjunto arqueológico. Las primeras inhumaciones parecen haberse iniciado en el Calcolítico Pleno, a juzgar por la presencia de platos de borde engrosado. En cuanto a la cronología del enterramiento de la Edad del Bronce, GAVILÁN y MORENO (1987: 365) se inclinan por una datación antigua en base a que "espadas similares a la nuestra son frecuentes en los enterramientos argáricos en la fase $\mathrm{A}^{\prime}$ y a que "existen (...) puñales con seis y ocho remaches dentro de todo el mundo argárico en su Fase A". Esta afirmación es discutible por cuanto, aún considerando a la pieza de Derrita como' 'espada", en la bibliografía esgrimida en apoyo de su asignación cronológica (RUIZ GALVEZ. 1977 y SCHÜBART, 1975b, quienes a su vez siguen a BLANCE, 1971) queda claro que:

A- La espada es un tipo que en El Argar aparece exclusivamente en urna, por lo que tendría una datación tardía (del Argar B).

B- Las espadas sustituirán en el Argar B a las alabardas (consideradas características del Argar A) como objetos de prestigio en los ajuares funerarios.

Por otro lado, LULL (1983: 175-178) ha demostrado la falsedad de los presupuestos tipológico-evolutivos planteados por BLANCE (y seguidos por SCHÜBART y RUIZ GALVEZ) para puñales y espadas en base a su asociación a cistas o urnas. En consecuencia, resulta complicado intentar asignar a un momento determinado de El Argar el enterramiento de Detrita, máxime cuando éste combina tipos metálicos argáricos con unos vasos cerámicos no argáricos y con un ritual funerario de deposición en cueva natural que contrasta con el seguido en el área nuclear de esta cultura. Planteada así la cuestión, será preciso esperar a que contemos con una visión más precisa del desarrollo de la Edad del Bronce en el Sur de la provincia de Córdoba, de su génesis y de la recepción de los influjos argáricos.

2.1.6. Cueva de la Murcielaguina (Priego de Córdoba). Esta cueva, muy conocida por sus materiales neolíticos, se abre al Barranco de las Angosturas, en la margen derecha del río Salado. De aquí procede un lote de materiales publicados como calcolíticos (GAVILÁN, 1987: Figs. 50 y 51). Consisten en:

- Cuenco de casquete esférico. 
- Fragmento de "cuemecillo".

- Fusaiola decorada con incisiones radiales.

- Fragmento de anillo de cobre de sección circular.

- Hacha plana de cobre de sección rectangular.

La presencia de las dos piezas metálicas hace bastante probable que nos encontremos en un Calcolítico avanzado, tal vez en su etapa ñnal, momento en que, como es bien sabido, se experimenta un cierto desarrollo metalúrgico. Estos objetos tal vez formaron parte de un ajuar funerario.

2.1.7. Cueva de Huerta Anguita (Priego de Córdoba). Se sitúa en las proximidades del Barranco de las Angosturas, en las estribaciones noroccidentales de la sierra de los Judíos, sobre la margen derecha del río Salado. De aquí procede una serie de restos arqueológicos, algunos de ellos considerados, por su asociación a restos óseos humanos, integrantes de un ajuar funerario (GAVILÁN, 1985):

- Puñal de $192 \mathrm{~mm}$. de longitud, con placa de enmangue triangular y cuatro remaches dispuestos en forma trapezoidal. La hoja aparece reforzada por un ancho nervio central que parte de la placa de enmangue (GAVILÁN, 1985). La posesión del nervio central, rasgo ajeno a la serie de puñales argíricos, nos lleva a considerar la posibilidad de que se trate de una alabarda. Sin embargo, la aplicación de los índices de LULL (1983b) demuestra que no nos hallamos ante una alabarda, aunque permite comprobar cómo muestra una notable similitud con los que obtuvimos para las piezas de Torre Benzalá y Fuente Tójar.

- "Brazalete de arquero" con dos perforaciones bipolares en cada extremo y sección circular.

- Hoja de sílex con retoque de uso.

- Varios fragmentos de bordes semiplanos, labiados, planos, apuntados y redondeados, así como alguna carena (GAVILÁN, 1987: 87 ss.).

La consideración de la Cueva de Huerta Anguita como área de deposición funeraria durante la Edad del Bronce nos parece evidente ante los datos que proporcionan ésta y otras cuevas de Priego. Sin embargo, la cronología del Argar A asignada por GAVILÁN al enterramiento de Huerta Anguita, en base a la asociación de un "brazalete de arquero" y de un puñal similar al nuestro con una alabarda en la sepultura 54 de Fuente Álamo (ARTEAGA-SCHÜBART, 1981), nos parece poco probable. No deseamos incidir de nuevo aquí en lo relativo que resulta inferir momentos cronológicos a partir de las asociaciones de ítems argáricos tras la revisión de LULL, pero sí señalaremos cómo el detalle del nervio que recorre la hoja del puñal de Huerta Anguita y la forma de su placa de enmangue, cuadran difícilmente con un momento antiguo de la Edad del Bronce. Además, los indudables paralelismos formales y morfométricos con las dagas de Fuente Tójar y Torre Benzalá y con la pieza (puñal, daga o alabarda) de El Laderón nos llevan a un momento más avanzado del Bronce \{vid. supra).

2.1.8. Cueva de los Mármoles (Priego de Córdoba). Como la anterior, constituye uno de los yacimientos más importantes del Neolítico cordobés (ASQUERINO, 1987), Se alza en la cota máxima de la Sierra de los Judíos, entre Priego y Almedinilla. Los materiales susceptibles de ser incluidos en las etapas que estudiamos son:

- Varios fragmentos de "cuernecillos" (GAVILÁN, 1987: 81).

- Fragmento de brazalete de arquero (GAVILÁN, 1987: Fig. 52,1). 
- Fragmento de vaso de carena baja (LÓPEZ PALOMO, 1977: 107; Lám. 5, núm. 30) y fragmento de borde con mamelón, ambos de superficies bruñidas.

- Varios fragmentos atípicos de cerámica pintada en rojo sobre engobe crema (ASQUERINO, 1985).

Como señala ASQUERINO, los fragmentos de cerámica pintada pueden encuadrarse tanto en el Neolítico Final como en el Calcolftico Antiguo. Los cuemecillos y tos "brazaletes de arquero" están presentes en todo el Calcolftico. El vaso carenado podría corresponder, por último, a cualquier momento de la Edad del Bronce.

2.1.9. Cueva de Cholones (Priego de Córdoba). Situada a poca distancia de la aldea de Zagrilla, en la Sierra de Alcaide, de ella proceden un cuenco hemiesférico de superficies bruñidas y un ídolo cruciforme fabricado en mármol o calcita (GAVILÁN, 1987b). El ídolo, del tipo B de ALMAGRO GORBEA (1973). presenta una amplia cronología que abarca desde el Calcolítico al Bronce Final. La referencia a la existencia de restos humanos hace plausible que ambas piezas formaran pane del ajuar de un entenamiento. Por último, debemos recordar las importantes pinturas esquemáticas de esta cueva (BERNIER-FORTEA. 1969).

2.1.10. El Pirulejo (Priego de Córdoba). Con este nombre se conoce una finca situada en las afueras de Priego de Córdoba, en la ladera oriental del afloramiento rocoso del Adarve. Precisamente en una grieta rocosa aparecieron los restos óseos correspondientes a un hombre adulto y a un niño de corta edad (ASQUERINO, 1985b). El material arqueológico consiste en:

- Vaso de carena baja acusada, galbo cóncavo y borde saliente.

- Cuenco hemiesférico con borde saliente.

- Vaso en forma de casquete esférico, con borde redondeado-apuntado muy exvasado.

ASQUERINO fecha este enterramiento dentro del Argar B en base a la presencia del vaso de carena baja. Aunque esta apreciación podría ser correcta, debemos recordar lo arriesgado que resulta operar con una sola variable a la hora de fijar cronologías, máxime cuando nos hallamos fuera del área para la que fueron establecidas y en la que, además, los últimos estudios (LULL, 1983) cuestionan el valor cronológico de la altura relativa de la carena en los vasos de las Formas 5 y 6 tal y como propusiera SCHÜBART (1975).

2.1.11. Los Castillejos (Carcabuey). El yacimiento se sitúa sobre un pequeño cerro en las estribaciones septentrionales de la Siena de Gaena, a escasa distancia de la margen derecha del rio Zagrilla. La valoración de este yacimiento se ha realizado en base al lote de materiales publicados por RUIZ LARA (1987) y a los recuperados en una prospección superficial.

- Seis vasos de pequeño tamaño (diámetro entre 20 y $60 \mathrm{~mm}$.), de superficies toscas, a los que se considera crisoles (RUIZ LARA, 1987: Fig. 2), aunque no presentan rastros de adherencias metálicas.

- Vasos de variada tipología, de perfil hemiesférico y globular, así como algunos carenados (RUIZ LARA, 1987: Fig. 3).

- Fragmentos de platos de borde engrosado (Fig. 4, núm. 4).

- Vaso bitroncocónico de superficies alisadas (RUIZ LARA, 1987: Fig, 4).

- Fragmento de base y galbo perteneciente a un vaso parabólica de superficies bruñidas. 
- Fragmento de galbo de un vaso de carena media y superficies bruñidas.

La ocupación calcolítica de este asentamiento viene corroborada por la presencia de los platos de borde engrosado. El vaso bitroncocónico es poco frecuente en el Calcolítico, máxime con una carena tan acusada, siendo en cambio característico de la cultura argánca (Forma 6 de Siret). También a la Edad del Bronce apuntan el vaso parabólico y el de carena media. En cuanto a los crisoles, de haber tenido realmente tal función, encajarían mejor en el Bronce que en el Cobre, dada la manifiesta pobreza de la metalurgia calcolítica en las Subbéticas.

2.1.12. El Castillarejo (Priego de Córdoba). Asentamiento ubicado sobre un cerro amesetado en la confluencia de los ríos Almedinilla y San Juan. El material arqueológico es relativamente abundante, en especial en la cima y la ladera oriental. De entre el numeroso material cerámico presentamos la siguiente selección:

- Vasos con perfiles derivados de la esfera: de cuarto de esfera, hemiesféricos y globulares (Fig, 2, núms. 1-6).

- Platos de borde engrosado, de variada tipología (Fig. 5, núms. 1, 4 y 6-8), entre ellos uno en " $\mathrm{T}$ ".

- Fuente o bandeja, de borde simple y base plana (Fig. 5, núm. 5).

- Vaso de carena baja y superficies bruñidas (Fig. 3, núm. 4),

La ocupación calcolítica de este poblado queda comprobada por la presencia de los típicos platos de borde engrosado. El de perfil en " $\mathrm{T}$ " apuntaría a un momento final de la Edad del Cobre. Es significativa la ausencia de fragmentos de fuentes carenadas entre el gran número de fragmentos recuperados por prospección. El único indicio positivo para considerar la continuidad del hábitat durante la Edad del Bronce viene dado por el vaso de carena baja y superficies bruñidas.

2.1.13. Cortijo de El Torcal (Priego de Córdoba). Se sitúa en el Pasillo de Carcabuey, flanqueado por las Sierras Horconera y Gaena, junto a la carretera que une Priego con Rute. De aquí procede una estela del Tipo I de ALMAGRO (1966) publicada por CANO NAVA (1977), con el relieve de un "ancoriforme" sobre la superficie de la losa. No entraremos en la interpretación del objeto representado en esta estela, pues nos alejaría de los objetivos propuestos y no aportaría nada novedoso a lo ya dicho (ALMAGRO, 1966; SCHÜBART, 1975).

En cambio, sí nos detendremos en la posición cronológica asignada a las estelas del Tipo I. ALMAGRO propone una datación entre el 1000 y el 800 a.C, fecha en la que serían sustituidas por las del Tipo II, Para ello se basa en la cronología por aquellos años supuesta para el tipo de espadas representadas en las estelas y en la consideración de una larga perduración de las alabardas. Sin embargo, al comentar el hallazgo de una de estas losas alemtejanas cubriendo la denominada "sepultura C" de la necrópolis de Santa Victoria, se ve obligado a reconocer que la tipología de los vasos cerámicos hallados en ésta y otras cistas del mismo tipo, los denominados por SCHÜBART (1971) "cuencos tipo Santa Vitoria", ofrece claras relaciones con el mundo argírico, por lo que se inclina a "considerar como propias del Bronce II o Bronce Medio todas estas necrópolis con las que debemos relacionar las estelas grabada de nuestro Tipo I" (ALMAGRO, 1966:205). Pese a todo, y obligado por una imperiosa necesidad de rebajar la cronología, considera este hecho como un rasgo más de ese supuesto "arcaísmo" que rodea las estelas alemtejanas, y se reafirma en la 
cronología del primer cuarto del I milenio a.C.

SCHÜBART $(1971 ; 1974 ; 1975)$ sigue muy de cerca los supuestos de ALMAGRO y sitúa las estelas en su Fase 11 de esta cultura, con un desarrollo entre el 1100 y el 900 y ciertas perduraciones hasta el 700 a.C. Sin embargo, no diferencia con nitidez las dos fases del Bronce del Suroeste, al tiempo que se aprecian ciertas incongruencias surgidas del hecho de la relativamente escasa documentación que define a esta cultura y, lo que es más importante, de que ésta proceda con exclusividad de contextos funerarios, desconociéndose casi por completo los poblados. Así, aunque sean factibles las correlaciones establecidas entre la Fase I y la cultura argárica en su Fase B, lo que nos daría un marco general para el desarrollo del Bronce del Suroeste a partir de mediados del II milenio, no acertamos a comprender, siguiendo a RU1Z GALVEZ (1984: 330 ss.) y a AUBET-SERNA (1981: 245), la adscripción de las estelas a una etapa tardía, mal definida desde el punto de vista ergológico y cultural y que, además, carece de armas metálicas entre los ajuares de sus sepulturas.

Esta última constatación, de aceptarse -lo que es difícil- la relación de todas las estelas del Tipo I de Almagro con cistas de la supuesta Fase II, podría abrir interpretaciones alternativas que contemplasen la ausencia de armas en sepulturas con estelas $y$ la presencia de armas en sepulturas sin estelas desde perspectivas distintas a las del mero desfase cronológico.

Sea como fuere, nos parece muy difícil que las estelas alemtejadas correspondan a un momento tan reciente como el sustentado por ALMAGRO y por SCHÜBART, debiéndose elevar su cronología hasta el Bronce Medio (ALMAGRO GORBEA, 1976; AUBETSERNA, 1981;RUIZGALVEZ, 1984).

La aparición de una estela de este tipo en un punto tan alejado del núcleo original del Bronce del Suroeste no deja de resultar sorprendente, constituyendo una prueba más del papel desempeñado por las tierras de las actuales provincias de Córdoba y Sevilla como transmisoras, y en parte catalizadoras, de influjos culturales entre el Sureste y el Suroeste de la Península Ibérica.

\section{Las pautas del poblamiento}

La red de poblamiento calcolítico en la zona en estudio está formada porcuatro poblados con un patrón de asentamiento bien definido. Se trata de hábitats ubicados en cerros amesetados, de gran extensión en el caso de la Mesa y más reducidos en los restantes. En todos los casos presentan una clara individualización de la topografía circundante y laderas escarpadas, lo que garantiza ciertas posibilidades defensivas, más acusadas en poblados como El Esparragal o El Castillarejo.

Por ahora no contamos con elementos para contemplar la existencia de fortificaciones. Tan sólo en El Castillarejo se observan ciertas alineaciones de piedras de poca entidad, de difícil y problemática interpretación en tanto no se proceda a la excavación, aunque por su situación topográfica y características parece improbable que correspondan a construcciones defensivas relacionadas con el asentamiento calcolítico. Por otro lado, no debemos olvidar que por todo el cerro se advierten restos de estructuras militares de la pasada Guerra Civil.

No es mucho lo que podemos deducir del tamaño de los asentamientos a partir de la simple prospección superficial, máxime cuando tampoco contamos con murallas que delimiten al menos el núcleo principal del poblado. Por otra parte, y si bien en algún caso hemos realizado prospecciones sistemáticas que nos han permitido controlar las pautas de 
dispersión/concentración del material, son bien conocidas las múltiples causas, tanto antrópicas como naturales, que inciden en la aparición de los restos arqueológicos en superficie.

Pese a todo, y ayudándonos de la propia configuración topográfica de los cerros amesetados sobre los que se ubican nuestros poblados, los indicios apuntan a asentamientos de pequeño tamaño, inferior a 0,5 Ha., para el caso de Los Castillejos, El Esparragal y El Castillarejo. Sóloen La Mesa pudo haber existido un poblado de mayor tamaño a juzgar por el volumen de materiales de superficie y su amplia área de dispersión, si bien la intensa acción antrópica -cultivos, repoblación forestal...- ha podido incidir en esta situación. Sin embargo, lo cierto es que mientras es difícil que cerros como El Castillarejo hayan servido de base, por su reducido tamaño, a núcleos de mayor entidad, la Mesa de Fuente Tójar pudo dar respuesta a hipotéticos incrementos demográficos plasmados en un aumento de la superficie del poblado.

Otro factor que interviene en la elección del lugar de asentamiento es el aprovisionamiento de recursos acuíferos, razón por la que todos los poblados se localizan junto a uno o más manantiales dé flujo intenso y constante.

Junto a las posibilidades defensivas y/o de control estratégico del territorio, y a la disponibilidad de agua, un tercer factor configurador del patrón de asentamiento es la explotación económica del territorio circundante. Es conocida la tendencia territorial de la mayor parte de las comunidades productoras sedentarias, que lleva a la constitución de territorios de producción restringida (T.P.R.) en los que se concentran la mayor pane de las actividades económicas básicas.

Los métodos de Geografía Locacional aplicados a la Arqueología Espacial han proporcionado un bagaje conceptual que permite estudiar las interrelaciones entre el asentamiento y su entorno ecológico-económico inmediato. El más usado es el análisis del territorio de captación (S.C.A.) que es el que presentamos en nuestra figura 7. En síntesis, este procedimiento parte de la consideración de un territorio circular, alrededor del poblado, del que se obtienen los recursos primarios (razón por la que, hasta ciertos niveles, podemos asimilarlo a) T.P.R,). La delimitación de ese territorio se viene admitiendo, de modo convencional para comunidades productoras, en un radio de $5 \mathrm{kms}$. tomando como centro el lugar de habitat. Estos $5 \mathrm{kms}$. vienen a coincidir, siempre que la orografía no sea en exceso accidentada o existan obstáculos físicos arduos de salvar, con la distancia que un hombre puede recorrer en una hora por sus propios medios físicos. $\mathrm{O}$ lo que es lo mismo, equivale a la distancia a la que es rentable el desplazamiento periódico desde un centro de residencia para atender las labores agrarias sin contar con medios de transpone. Al no estar constatados el empleo de animales de carga ni de la rueda en el Calcolítico andaluz, en principio consideramos viables estos postulados.

En el mapa de la Fig. 7 quedan reflejados los T.P.R, de los cuatro asentamientos calcolíticos documentados, a los que hemos añadido El Adarve de Priego, donde parece haber existido un poblado de la Edad del Bronce (ASQUERINO, 1985b) y que, con probabilidad, tuviera una fase calcolítica previa, hoy perdida bajo el actual casco urbano. Uno de los hechos que antes llama la atención es la relación entre poblamiento y tierras de mayor potencial agrícola. Así, cuatro de los cinco asentamientos considerados se sitúan junto a las vegas de los ríos Zagnlla, Salado y Almedinilla, zonas de irrigación natural en las que se practican cultivos de alto rendimiento. La Mesa de Fuente Tójar supone la única excepción, compensándose la carencia de tenenos de vega por la concentración a su 
alrededor de los únicos suelos rojos mediterráneos y tierras negras de la comarca, muy indicados para el cultivo intensivo de cereales.

La vocación agrícola es patente por el hecho de que entre el 80\% (La Mesa) y ei $40 \%$ (Los Castillejos) de los T.P.R. son aptos para el cultivo de cereales, y por el hallazgo de útiles usados en su recolección, almacenamiento y transformación (dientes de hoz, molinos barquiformes...). La cría de ovicápridos, aprovechando las extensiones de monte bajo, y de algún ganado vacuno y porcino complementaría las producciones básicas de estos poblados calcolíticos.

Por lo que respecta a la apropiación de otros recursos, debemos señalar el carácter en principio no determinante de este factor en la elección de la ubicación de los asentamientos. Así, materias primas como el sílex se encuentran lo bastante repartidas como para que todos los asentamientos dispongan de uno o varios puntos de aprovisionamiento dentro de sus respectivos T.P.R. Más restringidas se presentan en cambio las salinas, de las que sólo disponen El Castillarejo y La Mesa. Es bien conocida la importancia de la sal a lo largo de la Historia, tanto para usos culinarios y de conservación de alimentos como para su consumo por el ganado ovino, razón por la que podría plantearse su posible comercio intercomunitario. Lo mismo cabría decir para sustancias colorantes como la almagra, con importantes depósitos en las proximidades de La Mesa.

Como conclusión podemos afirmar que nos hallamos ante comunidades autosuficientes que obtienen sus recursos de T.P.R. bien delimitados y sin que, en principio, pueda establecerse una competencia por recursos críticos de desigual distribución espacial. La demanda de productos como la sal o sustancias colorantes pudo ser satisfecha mediante unos incipientes intercambios que en modo alguno creemos fueran capaces de influir sobre la configuración económico-social de las comunidades locales.

Más compleja se muestra en cambio la cuestión del abastecimiento de mineral de cobre. La carencia de recursos mineros en las subbéticas y áreas limítrofes obliga a la existencia de circuitos interregionales para el comercio del cobre, en bruto, elaborado o se $\mathrm{m}$; elaborado. Porel momentono contamos con tipos metálicos plenamente calcolíticos en los yacimientos subbéticos, no estando documentada la metalurgia hasta el tránsito a la Edad del Bronce, dentro de un horizonte paralelo a Cazalilla II-Albalate en la Campiña de Jaén.

RUIZ et alii (1986) destacan el posible papel de los asentamientos de la cuenca del Salado de Porcuna en la comercialización de metales procedentes de Sierra Morena durante el horizonte Cazalilla II-Albalate. Ya en el sector cordobés de la Campiña, encontramos el yacimiento de Guta (CARRILERO-MARTÍNEZ, 1985), que pudo desempeñar un papel similar en la cuenca del Guadajoz, captando el metal que alcanzaba el Guadalquivir desde Sierra Morena a través de los ríos Guadiato y Arenoso (MURILLO, 1986), todo ello dentro de un sistema de redistribución de productos minero-metalúrgicos similar al que se reproducirá durante el Bronce Final-Oriental izante (MURILLO, 1987e.p.;idem 1989 e.p.).

Noestamos aún en condiciones de calibrar en qué medida este comercio de metales pudo incidir en las comunidades del Cobre Final-Bronce de las Subbéticas, máxime cuando sólo parecen haber participado de forma marginal y como meros artífices de una demanda limitada. Con todo no parece haber sido lo suficientemente intensa como para incidir en los patrones de asentamiento, que sólo se verán modificados en el Bronce Final-Orientalizante. 


\section{La dinámica cultural}

Por lo que respecta a la caracterización ergológica del Calcolítico y de la Edad del Bronce de las Subbéticas y a su evolución diacrónica, carecemos de las bases firmes que podría proporcionamos el contar con secuencias estratigráficas para la zona, razón por la que deberemos recurrir a comparaciones con yacimientos excavados situados en áreas vecinas. En este sentido, nos resulta del máximo interés la confrontación con el poblado de Los Castillejos de Montefrío, situado a apenas $20 \mathrm{kms}$. de nuestros yacimientos.

En Los Castillejos está documentado un asentamiento al aire libre fundado en un horizonte cultural (Fase I) que muestra estrechas relaciones con la denominada "Cultura de las Cuevas" (NA V ARRETE, 1976), razón por la que ha sido calificada por los excavadores como Neolítico Tardío (ARRIBAS-MOLINA, 1978). Este se caracteriza por una industria lítica de clara componente laminar, con presencia de algún trapecio y, en especial, por cerámicas decoradas (almagras, incisas, pintadas e impresas). Una transformación esencial seopera en Montefrío II, con una disminución de los motivos decorativos y un clarodominio de la cerámica no decorada. Junto a las arcaicas formas globulares, simples o con cuello, encontramos ahora escudillas y cuencos hemiesféricos, así como grandes fuentes carenadas que serán definitorias de la etapa.

Este horizonte de las fuentes carenadas, considerado por algunos investigadores Neolítico Final y por otros Calcolítico Inicial, alcanzará una amplia distribución por el Sur peninsular (MARTIN DE LA CRUZ. 1985; RUIZ MATA, 1983; TAVARES-SOARES. 1977). En este momento parece iniciarse la ocupación de La Mesa y de El Esparragal, únicos yacimientos en los que tenemos comprobada la presencia de fuentes carenadas. En La Mesa están documentadas además una importante industria lítica, cerámicas a la almagra, cerámicas pintadas en rojo sobre engobe crema con sencillos diseños geométricos y brazaletes de mármol sin decoración. Todo ello nos sitúa en un ambiente muy similar al de Montefrío II.

En la inmediata Campiña del Guadajoz esta fase está bien definida en yacimientos como Morales (CARRILERO et alii, 1982)o ViñaBoronato(CARRILERO-MARTÍNEZ, 1985). También la hallamos en el Cerro de Santa María y en La Minilla (RUIZ LARA, 1986), ya en la Campiña Occidental cordobesa. En el Valle Medio del Guadalquivir aparecen fuentes carenadas en Algallarín (MURILLO, 1986), El Chaparral y Cerro de los Peces (MURILLO, 1988). Por último, los yacimientos de Huerta del Caño (MURILLO, 1986) en el Valle del Guadiato, y de La Longuera (MURILLO et alii, 1988) en el corazón de Los Pedroches, marcan la presencia de este ítem en la mitad septentrional de la provincia de Córdoba.

Resta aún por definir el origen del horizonte cultural de las fuentes carenadas dadas las deficiencias de las secuencias estratigráficas que cubren el tránsito desde el Neolítico al Calcolítico. Estas, obtenidas fundamentalmente en cuevas (Nerja, Dehesilla, Cueva Chica de Santiago), sólo ofrecen una parte, por lo demás sesgada, del proceso, pues nos ilustran un proceso de transición desarrollado por grupos que siguen anclados en los viejos modelos neolíticos. Las innovaciones debieron partir de los grupos que antes rompieron con las estructuras neolíticas al vivir en poblados al aire libre como Los Castillejos de Montefrío.

Así pues, planteamos como hipótesis que es en el cambio radical de estructuras producido en un momento aún oscuro del Neolítico Final y que lleva al abandono del hábitat en cueva y a la fundación de asentamientos estables al aire libre por parte de grupos portadores de una cultura tardoneolítica, en el que debemos rastrearel origen del Calcolítico 
andaluz. En cuanto a la causa de tal proceso, creemos que éste ha de buscarse dentro de la lógica resultante del papel cada vez más importante de la agricultura desde el Neolítico Medio en el seno de las comunidades más dinámicas (PELLICER-ACOSTA, 1982; RUBIO, 1988). Esto, unido al probable aumento demográfico resultante de unos medios de subsistencia cada vez más diversificados, llevaría a una auténtica "colonización" de las tierras bajas de la periferia de las Cordilleras Béticas, zona nuclear del Neolítico Antiguo y Medio Andaluz.

Hasta el momento los más antiguos asentamientos neolíticos andaluces al aire libre parecen ser los del litoral onubense (PIÑÓN, 1988), si bien aquí las altas cronologías (del V milenio), las estrechas relaciones con el Sur de Portugal y la coexistencia de actividades agrícolas y ganaderas con el aprovechamiento del medio costero, introducen variables que divergen del modelo planteado. Tal vez encontremos una explicación a estas peculiaridades en que estos poblados sean monofásicos, no perdurando ninguno de ellos durante el Calcolítico, momento en el que son sustituidos por asentamientos tipo Papau vas.

Algo posterior, y ya dentro del proceso que estamos describiendo, sería el poblado de la Fase I de Montefrío y el del Cerro del Castellón de Campotéjar (NAVARRETE, 1986). Morales y otros asentamientos de la Campiña cordobesa también iniciarían su ocupación en los últimos momentos de) Neolítico (CARRILERO-MARTÍNEZ, 1985), al igual que La Mesa de Fuente Tojar y, con probabilidad, El Esparragal.

En consecuencia, debe buscarse en estos poblados agrícolas de las tierras bajas el origen de las fuentes carenadas, que parecen responder a un cambio en la dieta y, tal vez, en el comportamiento social en comunidades cada vez más despendientes de una agricultura cerealista. Es significativo que la aparición de las fuentes carenadas en Montefrío II coincida con el desarrollo de la agricultura y con el descenso de los ovicáprídos (ARRIBASMOLINA, 1978; RUBIO, 1988). El proceso se consolidará en Montefrío III, acompañado de un significativo incremento de las actividades cinegéticas (ARRIBAS, 1986).

A partir de este momento quedan fijados los rasgos básicos del Calcolítico, viniendo marcado su proceso diacrónico por una serie de tipos cerámicos -platos de borde engrosado para el Calcolítico Pleno y cerámica campaniforme para el Final-. Las transformaciones en las estructuras económicas y sociales, más profundas y por ello más difíciles de aprehender, continuarán sin embargo a lo largo de todo el penodo. La incidencia que sobre este proceso tuvo la introducción de la metalurgia ha sido uno de los temas más controvertidos. Frente a lo que se ha venido admitiendo durante décadas, en los últimos años se tiende a no considerar la metalurgia rasgo distintivo del Calcolítico, capaz por sí misma de servir de motor a las profundas y complejas transformaciones que se hacen patentes a partir de esta etapa. Antes bien, creemos que la raíz de esta dinámica se encuentra en un incremento de la explotación agrícola, con la introducción de técnicas rotatorias dentro de un policultivo cerealista, de métodos de irrigación y de nuevas especies vegetales (MARTIN SOCAS, 1978). Este proceso pudo conducir a una incipiente jerarquización social (CHAPMAN, 1981; RAMOS MILLAN, 1981), con aparición de jefaturas (GILMAN, 1976) y articulación en comunidades territoriales, de las cuales las sepulturas colectivas megalíticas serían indicadores de control del territorio (RENFREW, 1976; 1984) y elementos de cohesión comunitaria (CHAPMAN, 1981).

Entendemos que el inicio de la metalurgia peninsular ha de contemplarse inmerso en esta dinámica, posiblemente como resultado de la evolución autónoma de ciertas comunidades del Neolítico FinaTCalcolítico Inicial, que en su intensiva explotación de los respectivos 
ámbitos territoriales comienzan a utilizar el cobre y a adentrarse en los secretos de su metalurgia, que sólo se desarrollará en los momentos finales de este período, de modo paralelo a la difusión de la cerámica campaniforme, hasta alcanzar su máximo florecimiento en época argáríca.

Circunscribiéndonos ya al ámbito espacial de nuestro trabajo, comprobamos que tras los inicios del poblamiento calcolítico, éste se estabiliza durante el Cobre Pleno, con una serie de poblados que articulan el territorio y proceden a su explotación de un modo que podríamos calificar de sistemático (vid. supra). La metalurgia tiene escasa incidencia, tal vez por su alejamiento de los depósitos mineros y por la inexistencia aún de los primeros canales de distribución. El ritual funerario predominante, aunque no contamos con demasiada documentación, parece haber sido la inhumación colectiva en cuevas naturales. Durante el Calcolítico Final, el área se muestra un tanto al margen de las nuevas corrientes representadas por el horízontecampaniforme. La no localización de cerámica campaniforme ni de tipos metálicos típicos de estos momentos (puñales de lengüeta) -con la única excepción de las supuestas puntas de Palmella de La Mesa- apunta en esta dirección, frente a lo que se comprueba en la Campiña cordobesa en yacimientos como Guta (CARRILEROMARTÍNEZ, 1985) y en tajiennense, en contextos del Horizonte Cazalilla II-Albalate, que marcan el tránsito a la Edad del Bronce.

Durante esta última etapa parecen mantenerse las tendencias de la fase anterior, sin aparecer los primeros influjos "argáricos" hasta un momento relativamente avanzado, y siempre como elementos indirectos y aislados dentro de un ambiente conservador; así lo atestiguaría la continuidad de los enterramientos en cuevas naturales y el mantenimiento del mismo patrón de asentamiento. La cronología de estos primeros contactos es por el momento imprecisa, aunque contamos con algunos indicadores indirectos. Así, parece aceptarse que la expansión de la cultura argáríca no se inicia hasta un momento en tomo al 1650 a.C. (LULL, 1983). En la zona occidental de Granada, la expansión se produjo tras la Fase de Formación (Argar A), actuando sobre un sustrato de poblaciones megalíticas del Cobre Tardío-Final (AGUAYO, 1986). En consecuencia, nos parecedifícit que, en el estado actual de la investigación, se pueda mantener una filiación de El Argar A para los enterramientos de La Detrita y Huerta Anguila (vid supra). Esta receptividad de las Subbéticas cordobesas coincide con un momento de efervescencia cultural en las diversas áreas de la Edad del Bronce del Sur Peninsular, al encontrarse en las proximidades de tas principales rutas que unen el foco argárico con el Bronce del Guadalquivir y con el del Suroeste. De otro modo, no tendría sentido la presencia en nuestra área de los tipos metálicos arriba analizados ni de la Estela de El Torcal.

Sólo en el Bronce Final-Oríentalizante, tal como ya hemos expuesto (MURILLO et alii, 1989) se advierte una modificación profunda de las estructuras iniciadas al fina] del Neolítico, con un cambio efectivo en el patrón de asentamiento (Fig. 8). El habitat de la Mesa se traslada, sin que por el momento sea posible conocer las causas, al cercano Cerro de las Cabezas, en cuya superficie aparecen algunos materiales de este momento. A estos habría que añadir el hallazgo en Fuente Tójar de un hacha de talón con dos anillas laterales y con cono de fundición intacto (MONTEAGUDO 1977:173, $\mathrm{n}^{\mathrm{a}}$ 1059; Fig. 70), similar a otra al parecer procedente de Almedinilla (MONTEAGUDO, 1977:175, $\mathrm{n}^{\mathrm{a}}$ 1083; Fig. 72). Ambas vienen a atestiguar, junto a la espada del Cerro del Castillo de Carcabuey (HARRISON, 1974), cómo la zona continúa desempeñando su papel de encrucijada de caminos, abierta a los influjos de distintas áreas culturales (MURILLO-RUIZ LARA, 
1990).

Un proceso similar al de La Mesa se advierte en El Esparragal, que deja de habitarse en algún momento de la segunda mitad del II milenio, para situarse el poblado del I milenio en El Tarajal, a escasos $2 \mathrm{~km}$. de distancia, sobre un gran cerro amesetado en el centro de la confluencia de los ríos Zagrilla y Salado.

Lo mismo cabe decir para el poblado de Los Castillejos, sustituido por el asentamiento del Cerro del Castillo de Carcabuey (MURILLO-RUIZ LARA, 1990) que aparte de una superficie más extensa para el desarrollo del habitat tiene una privilegiada posición estratégica en la confluencias de las dos vías naturales de penetración hacia el centro de la comarca desde el Oeste y desde el Sur, En los alrededores de Priego no tenemos noticias de la existencia de ningún asentamiento del Bronce Final Sin embargo, al Sur de esta localidad encontramos el importantísimo poblado de Las Lagunillas, cuya ocupación parece iniciarse ahora y llegar hasta plena época ibérica (VAQUERIZO, 1984). De nuevo hallamos aquí un asentamiento con un claro sentido estratégico de control de una importante vía natural de comunicación.

El Castillarejo no presenta indicios de su ocupación durante el Bronce Final y el Orientalizante, en tanto que la prospección de su entorno no ha mostrado ningún yacimiento encuadrable en estos momentos. Por último, al Norte de Fuente Tójar, en la confluencia de los ríos Salado y San Juan, se alza sobre un amplio cerro amesetado el yacimiento de La Almanzora, que completa la distribución del poblamiento de los primeros momentos de la Protohistoria en la zona que venimos estudiando (MURILLO et alii, 1989), justo en el lugar en el que la depresión Priego-Alcaudete se abre a la Alta Campiña cordobesa.

\section{Bibliografía}

ACOSTA, P. (1986): El Neolítico en Andalucía occidental: estado actual. Homenaje a Siret,pp. 136-151.

AGUAYO, P. (1986): La transición de la Edad del Cobre a la Edad del Bronce en la provincia de Granada, Homenaje a Siret, pp. 262-270.

ALMAGRO, M. (1966): Las estelas decoradas del Suroeste peninsular, Madrid.

ALMAGRO GORBEA, M. (1972): La espada de Guadalajara y sus paralelos peninsulares.T.P, 29, pp. 55-82.

ALMAGRO GORBEA, M. (1976): La espada de Entrambasaguas. Aportación a la secuencia de las espadas del Bronce en el Norte de la Península ibérica, XI Aniversario del Centro de Estudios Montañeses, pp. 455-577.

ALMAGRO GORBEA, M. (1976b): Recensión a DieKuítur derBronzezeit imSudwesten der íberischen Halbinsel, de H. Schübart, T.P., 33, pp. 411-416.

ALMAGRO GORBEA, MJ. (1973): Los ídolos del Bronce $l$ en la Península Ibérica, Madrid.

ARRIBAS, A. (1986): La época del Cobre en Andalucía oriental: perspectivas de la investigación actual. Homenaje a Siret, pp. 159-166.

ARRIBAS, A. et MOLINA, F. (1978): El poblado de Los Castillejos en las Peñas de los Gitanos (Montefrio, Granada). Campañas de excavaciones de 1971. El Corte I, Granada.

ARTEAGA.O. et SCHÜBART, H. (1981): Fuente Alomo. Campaña de 1979, N.A.H., 11, pp, 7-32, Madrid.

ASQUERINO, M.D. (1985b): Sepultura argárica en Priego de Córdoba, B.R.A.C., 
109,pp.183-187.

ASQUERINO, M.D. (1985): Cerámicas pintadas de la Cueva de los Mármoles, XVII C.N.A.,pp. 239-248.

ASQUERINO, M.D. (1987): Cueva de los Mármoles (Priego de Córdoba). Avance de las campañas de excavación ;98211986, Ifigea, IH-IV, pp. 239-249.

AUBET, M.E. et SERNA, M.R. (1981): Una sepultura de la Edad del Bronce en Setefilla (Sevilla), T.P., 38, pp. 225-255.

BERNIER, J. et FORTEA, J. (1969): Nuevas pinturas esquemáticas en la provincia de Córdoba. Avance de su estudio, Zephyrus, XIX-XX, pp. 143-164.

BERNIER, J. et alii (1981): Nuevos yacimientos arqueológicos en Córdoba y Jaén, Córdoba.

BLANCE B. (1971): Die Anfange der Metallurgie auf der Iberischen Halbinsel, Berlfn.

CANONAVA,M.L.(1977): Una estela de tipo alemtejano en la provincia de Córdoba, T.P., 34, pp. 331-340.

CARRASCO, J. et PACHÓN, J. (1986): La Edad del Bronce en la provincia de Jaén, Homenaje a Siret, pp. 361-377.

CARRASCO, J. et alii (1980): Hallazgos del Bronce Final en la provincia de Jaén. La necrópolis de Cerro Alcalá, Torres (Jaén), C.P.Gr., 5, pp. 221-236.

CARRIAZO J. de M. (1947): La Edad del Bronce, Historia de España de Menéndez Pidal, Tomo I. vol. 1, pp. 755-852.

CARRILERO, M. et alii (1982): El yacimiento de Morales (Castro del Río, Córdoba). La cultura de los silos en Andalucía occidental, C.P.Gr., 7,pp. 171-205.

CARRILERO, M. et MARTÍNEZ, G. (1985): Eiyacimiento de Guta (Castro del Río. Córdoba) y la Prehistoria Reciente de la Campiña cordobesa, C.P.GT., 10, pp. 187-223.

CHAPMAN, R. (1981): Los Millares y la cronología relativa de la Edad del Cobre en el Sudeste de España, C.P.Gr., 6, pp. 75-91.

GAVILÁN, B. (1985): Puñal y brazalete de arquero de la cueva de Huerta Anguila, B.R.A.C., 109,pp. 179-181.

GAVILÁN, B. (1987): Los materiales de la Prehistoria en Priego de Córdoba, Córdoba.

GAVILÁN, B. (1987b): ;dolo cruciforme de la cueva-sima de Cholones (Zagrilla, Priego de Córdoba), Ifigea, IH-IV, pp. 251-253.

GAVILÁN, B. et MORENO, A, (1987): Avance sobre el enterramiento argárico de la Cueva de laDetrita (Priego de Córdoba), XVIII C.N.A., pp. 363-371.

GILMAN, A. (1976): Bronze Age dinamic in Soumeast Spain, Dialectical Anthropology, I, pp. 307-319.

HARRISON, R. (1974): Nota acerca de algunas espadas del Bronce Final de la Península ibérica, Ampurias, 35-36, pp. 225-233.

LÓPEZ PALOMO, L. A. (1977): Contribución al estudio del Neolítico y de la Edad del Bronce en Andalucía. i: la Cueva de los Mármoles, de Priego (Córdoba), Corduba, 5, pp. 69-108.

LULL, V. (1983): La Cultura de El Argar, Madrid.

LULL, V. (1983b): Contribución al estudio tipológico de las alabardas argáricas, XVI C.N.A..pp. 189-205.

MARTIN DE LA CRUZ, J.C. (1985): Papauvas $f$, Aljaraque, Huelva. Campaña de 1976 a 1979, E.A.E., 136, Madrid.

MARTIN SOCAS, D. (1978): Aproximación a la economía de la mitad meridional de 
la Península ibérica durante el Eneolítico, Zephyrus, XXVIII-XXIX, pp. 163-190.

MARTÍNEZ SANTA-OLALLA, J. (1935): La cultura portuguesa en el Alto Valle del Guadalquivir, A.M.S.E.A.E.P., XIV, pp. 260-261.

MONTEAGUDO, L. (1977): Die Beile aufder Iberischen Halbinsel, P.B.F., IX, 6.

MURILLO, J.F. (1986): Eneolítico y Edad del Bronce en el Norte de la provincia de Córdoba, Memoria de Licenciatura, Universidad de Córdoba.

MURILLO, J.F. (1986): Nuevos yacimientos calcoltticos en el sector noroccidental de la provincia de Córdoba, E.P.C., I, pp. 77-94.

MURILlO, J.F. (1988): Aproximación al poblamiento calcolítico en el Valle del Guadalquivir; sector Villarrubia-Palma del Rio, Ariadna, 4, pp. 3-25.

MURILLO, J.F. (1988 e.p,): Poblamiento protohistórico y minería en el Norte de la provincia de Córdoba, I Coloquio de Historia Antigua de Andalucía, Córdoba.

MURILLO, J.F. et alii (1987): Materiales calcolíticos procedentes de La Longuera, El Viso (Córdoba), Córdoba.

MURILLO, J.F. et alii (1989): Aproximación al estudio del poblamiento protohistórico en el sureste de Córdoba: unidades políticas, control del territorio y fronteras, Fronteras, III Coloquio Internacional de Arqueología Espacial, pp. 151-172.

MURILlO, J.F. et RUIZ LARA, D. (1990): El Cerro del Castillo de Carcabuey. Un yacimiento del Bronce Final-Orientallzante en las subbéticas cordobesas. Encuentros de Historia Local: La Subbética, pp. 33-59, Córdoba.

NAVARRETE, M.S. (1976): La Cultura de las Cuevas con cerámica decorada en Andalucía Oriental, Granada.

NAVARRETE, M.S. (1986): Las comunidades neolíticas en la Alta Andalucía, Homenaje aSiret.pp. 109-118.

NOCETE,F(1989): El espacio de la coerción. La transición al Estado en las Campiñas del Alto Guadalquivir (España) 3000-1500 a.C. ,B.A.R.,Monogr, of Spain and Portuguese Arch., 1, Oxford.

PELliCER, M. et ACOSTA, P. (1982): El Neolítico Antiguo en Andalucía occidental, Le Néolitique ancien méditerranéen, Montpellier, pp. 48-60.

PERICOT, L. (1942): La España Antigua, Historia de España, Instituto Gallach, vol. I, Barcelona.

RAMOS MILLAN, A. (1981): Interpretaciones secuenciales y culturales de la Edaddel Cobre en la zona meridional de la Península Ibérica. La alternativa del materialismo cultural. C.P.Gr., 6, pp. 203-256.

RENFREW, C. (1976): Megalithic, terrilories and population, IV Atlantic Coloquium, pp. 198-200.

RUBIO, I. (1988): La economía de subsistencia en el Neolítico hispano, en P. López (coord.), El Neolítico en España, pp. 337-417, Madrid.

RUIZ GALVEZ, M. (1977): Nueva aportación al conocimiento de la cultura de El Argar, T.P., 34, pp.i5-107.

RUIZ GALVEZ, M. (1984): Reflexiones terminológicas en torno a la Edad del Bronce peninsular, T.P., 41, pp. 323-342.

RUIZ LARA, D. (1987): Calcolítico y Edad del Bronce en la Campiña de Córdoba: aproximación a su estudio, E.P.C., 2, pp. 61-88.

RUIZ LARA, D. (1987b): Materiales calcolíticos de El Castillarejo (Carcabuey, Córdoba), Ifigea, III-IV, pp. 229-237. 
RUIZ LARA, D. (1988): Estado actual de la investigación sobre el Calcolltico en la Campiña de Córdoba, E.P.C., 4, pp. 41-57.

RUIZ MATA, D. (1983): El yacimiento de la Edad del Bronce de Valencina de la Concepción (Sevilla) en el marco cultural del Bajo Guadalquivir, I Congreso de Historia de Andalucía, Prehistoria y Arqueología, pp. 183-208, Córdoba.

RUIZ RODRÍGUEZ, A. et alii (1986): La Edad del Cobre y la argarización en tierras jiennenses, Homenaje a Siret, pp. 271-286.

SCHÜBART, H. (1971): Acerca de la cerámica del Bronce Tardío y Final en el Sur y Oeste peninsular, T.P., 28, pp. 153-182.

SCHÜBART, H. (1973): Las alabardas tipo Montejícar, Estudios dedicados al Dr. D. Luis Pericot, pp. 247-269, Barcelona.

SCHÜBART, H. (1974): La cultura del Bronce en el Sudoeste peninsular. Distribución y definición, Miscelánea Arqueológica 25 Aniversario de los Cursos de Ampurias, pp. 345370, Barcelona.

SCHÜBART, H. (1975): Die Kultur der Bronzezeit im Südwesten der Iberischen Halbinsel, Berlín.

SCHÜBART, H. (1975b): Cronología relativa de la cerámica sepulcral en la cultura de El Argar, T.P., 38, pp. 79-92.

SCHÜBART, H. et ARTEAGA, O. (1986): Fundamentos arqueológicos para el estudio socio-económico y cultural del área de El Argar, Homenaje a Siret, pp. 289-307.

TAVARES, C. et SOARES, J. (1977): Contribucao para o conhocimiento dos povoados calcolíticos deo Baixo Alemtejo e Algarve. Setúbal Arqueológica, II-III, pp. 179-272,

VAQUERIZO, D. (1984): Notas sobre material ibérico conservado en el Museo Arqueológico municipal de Priego deCórdoba (Córdoba). Corduba Archaeologica, 14, pp. 11-25.

VAQUERIZO, D. (1990): Novedades de Arqueología en Almedinilla (Córdoba), Encuentros de Historia Local: La Subbetica, pp. 61-77, Córdoba.

VICENT, A.M, et MUÑOZ, A.M. (1973): Segunda campaña de excavaciones en la Cueva de los Murciélagos, Zuheros (Córdoba), 1969. E.A.E., 77, Madrid. 


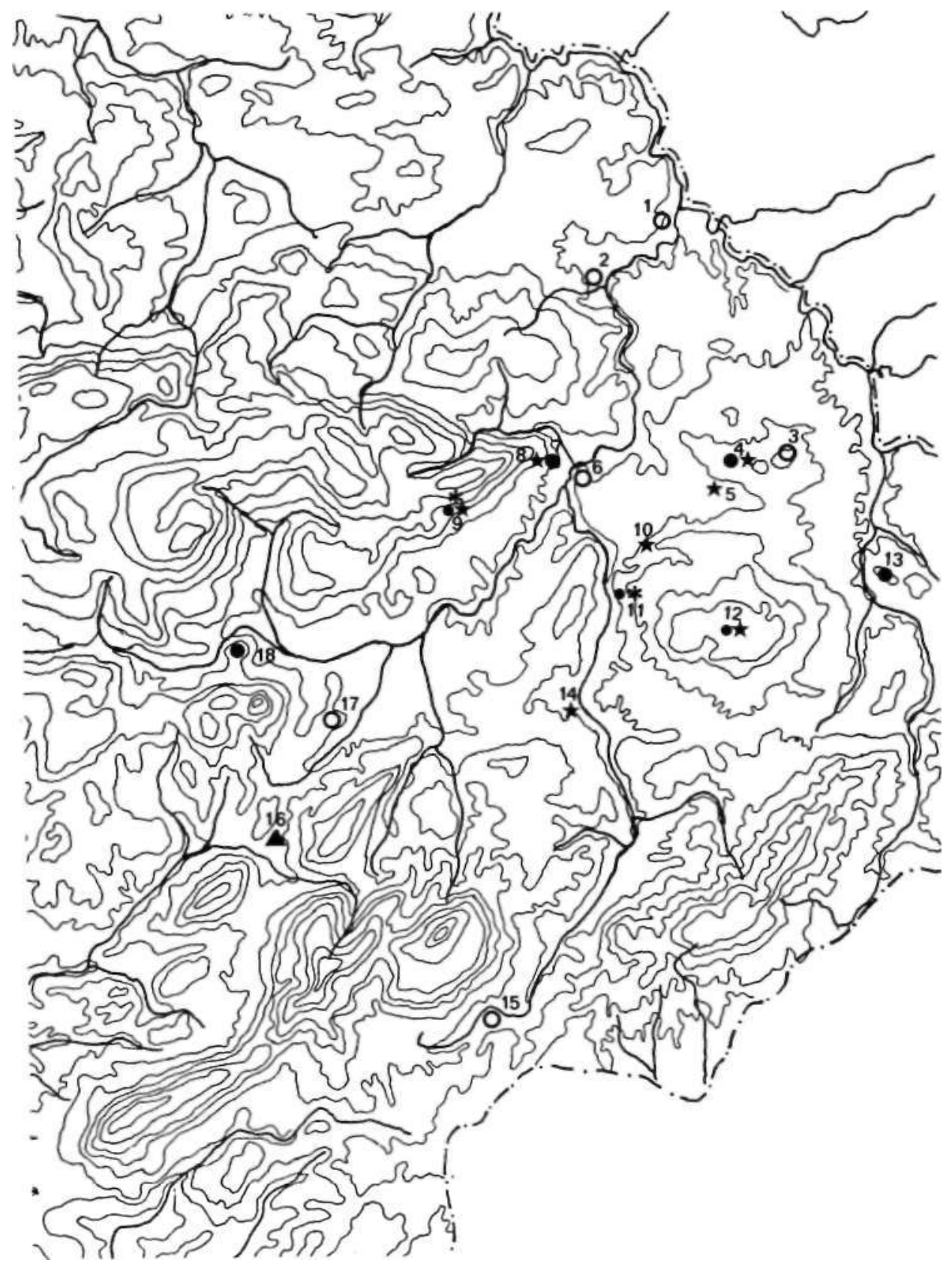

Fig. 1. Mapa con la distribución de los yacimientos encuadrables en el Calcolftico y la Edad del Bronce.

1. La Almanzora; 2. El Salobrar; 3. Cerro de las Cabezas; 4. La Mesa; 5. El Cañuelo; 6. El Tarajal; 7. El Esparragal; 8. Del rila; 9. Cholones; 10. Huerta Anguila; 11. Murcielaguina; 12. Mármoles; 13. El Castillarejo; 14. El Pirulejo; 15. Las Lagunillas; 16. El Torcal; 17. Castillo de Carcabuey; 18. El Castillejo. 


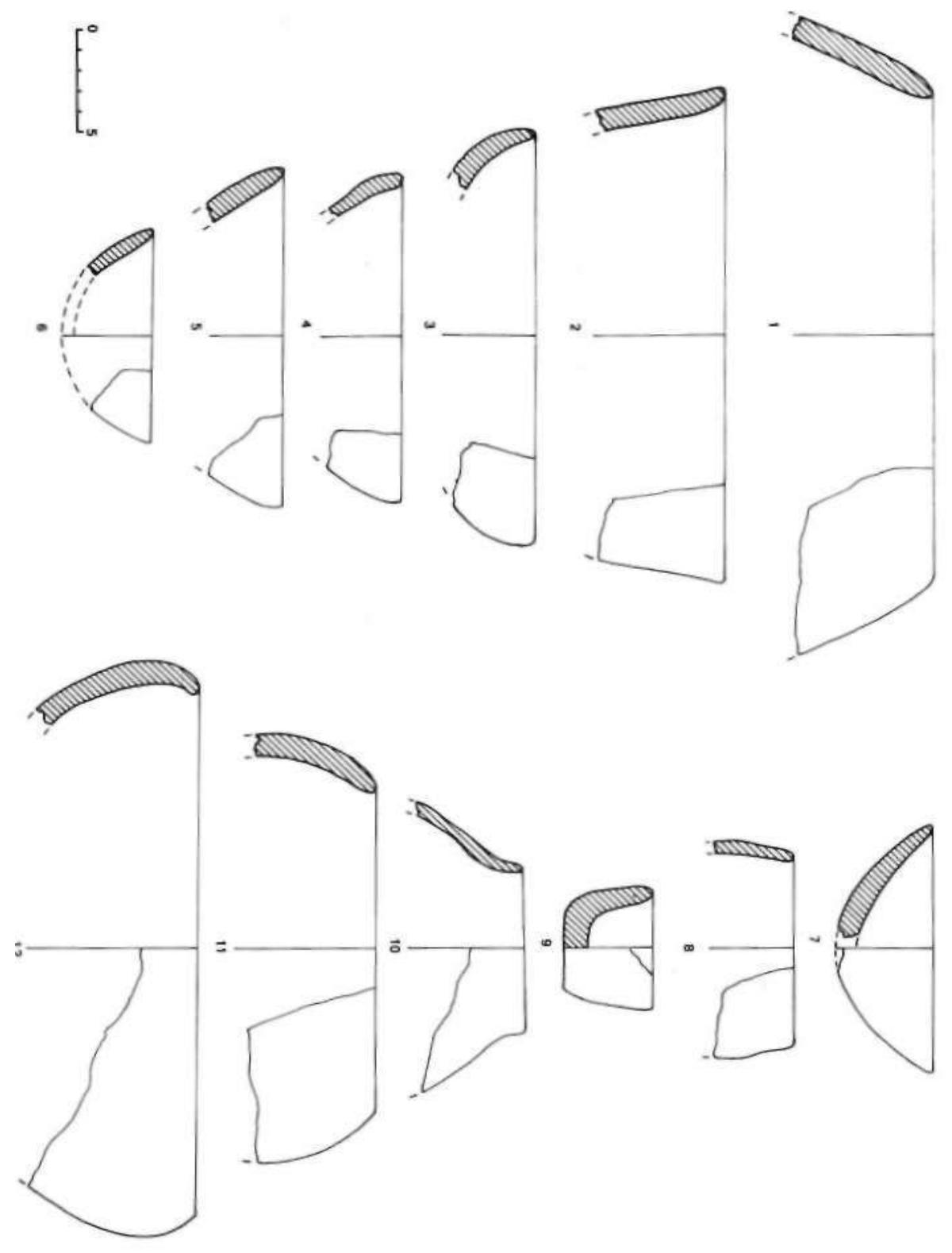

Fig. 2. Selección de material cerámico. 

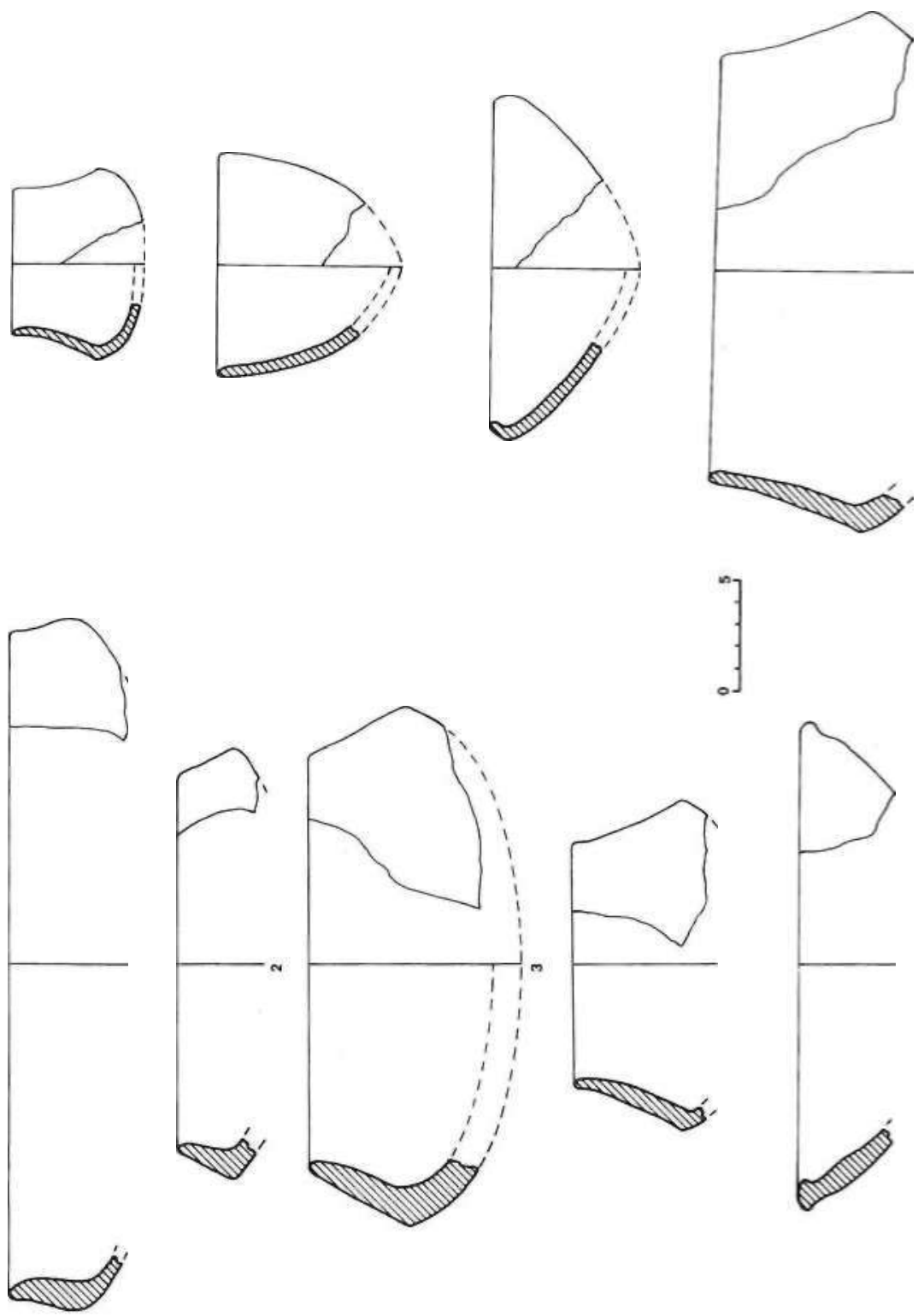

Fig, 3. Selección de material cerámico.

--- Grupo de investigación P.A.I. HUM 236 | http://www.arqueocordoba.com/publ/anales.htm --- 

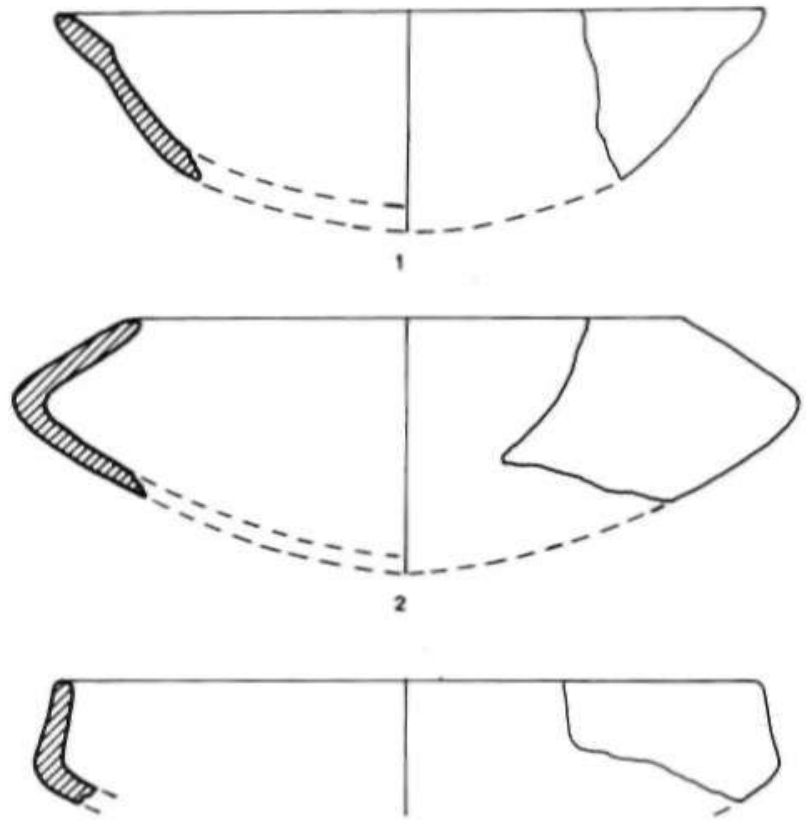

3
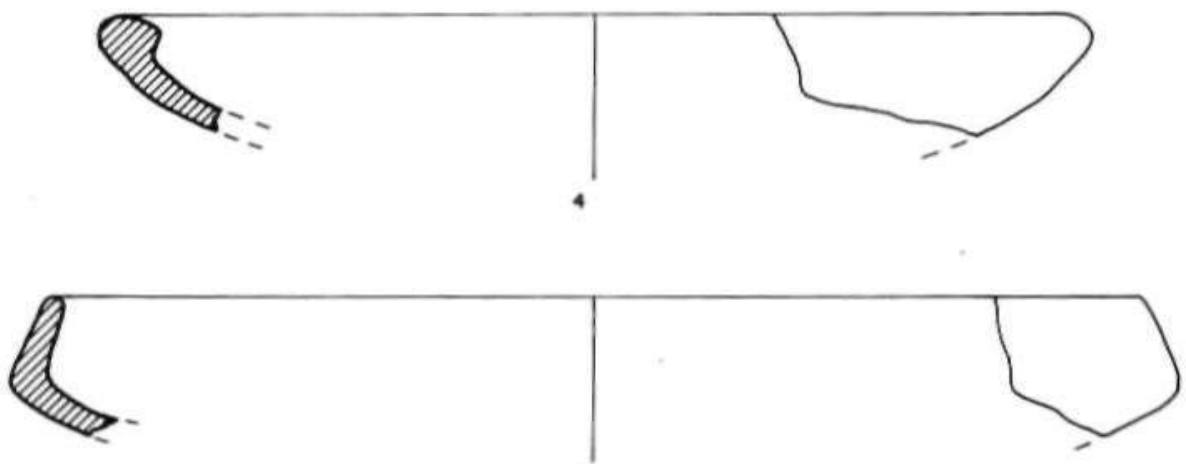

5
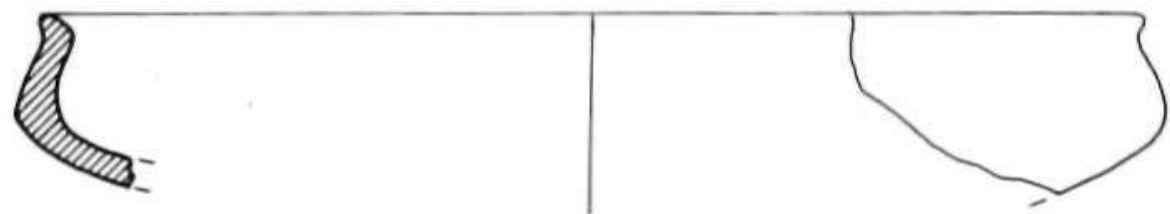

Fig, 4, Selección de material cerámico.

--- Grupo de investigación P.A.I. HUM 236 | http://www.arqueocordoba.com/publ/anales.htm --- 

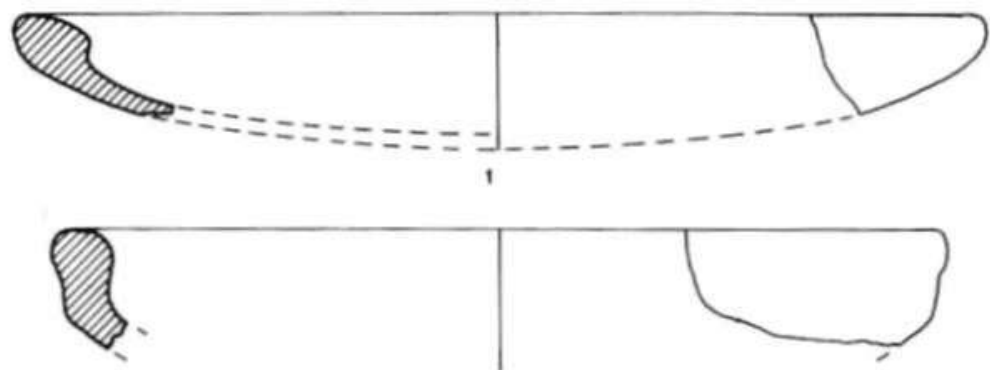

2
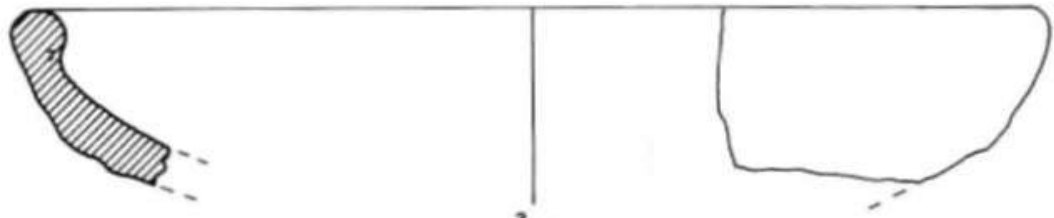

3
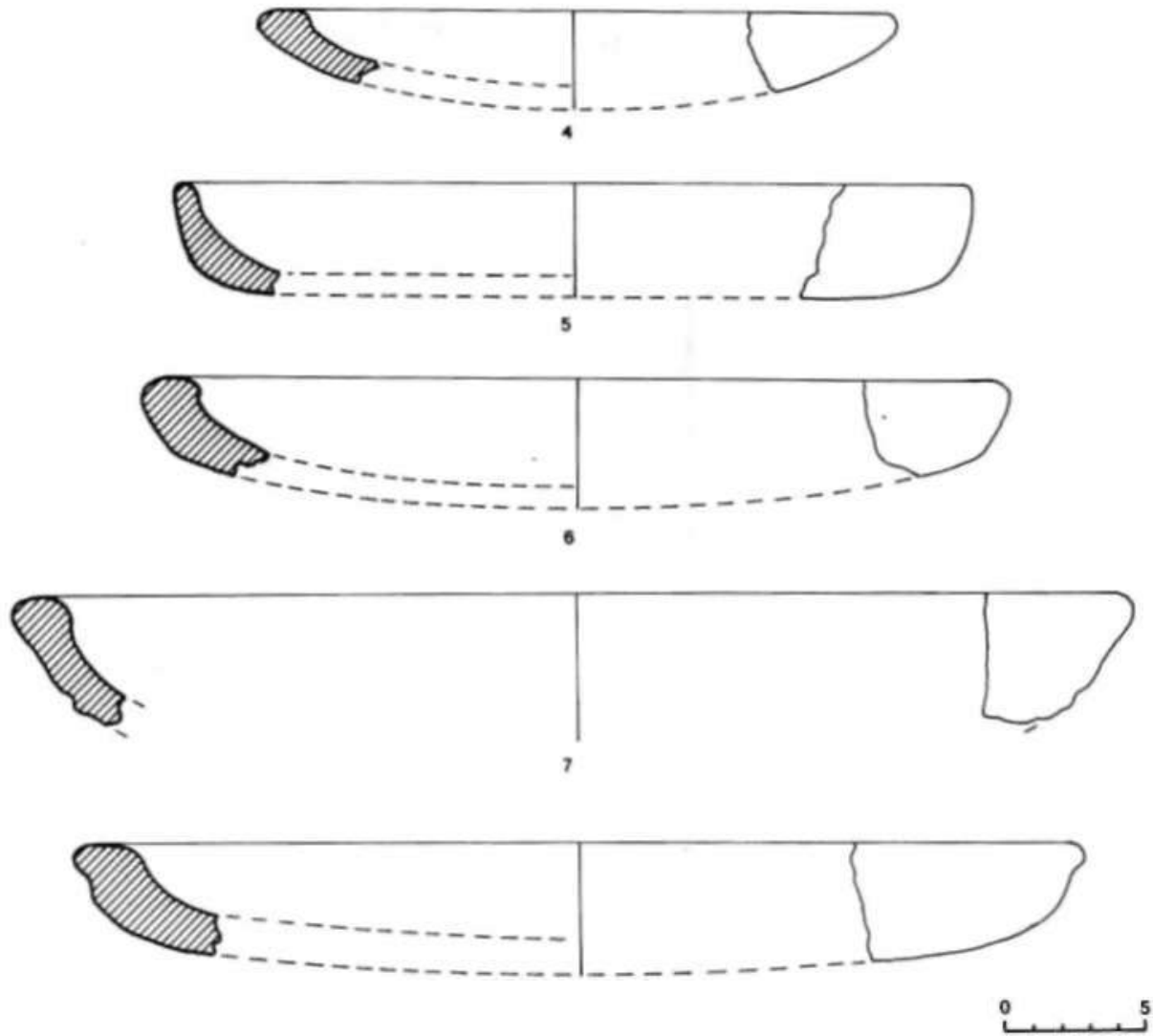

Fig. S. Selección de material cerámico.

--- Grupo de investigación P.A.I. HUM 236 | http://www.arqueocordoba.com/publ/anales.htm --- 


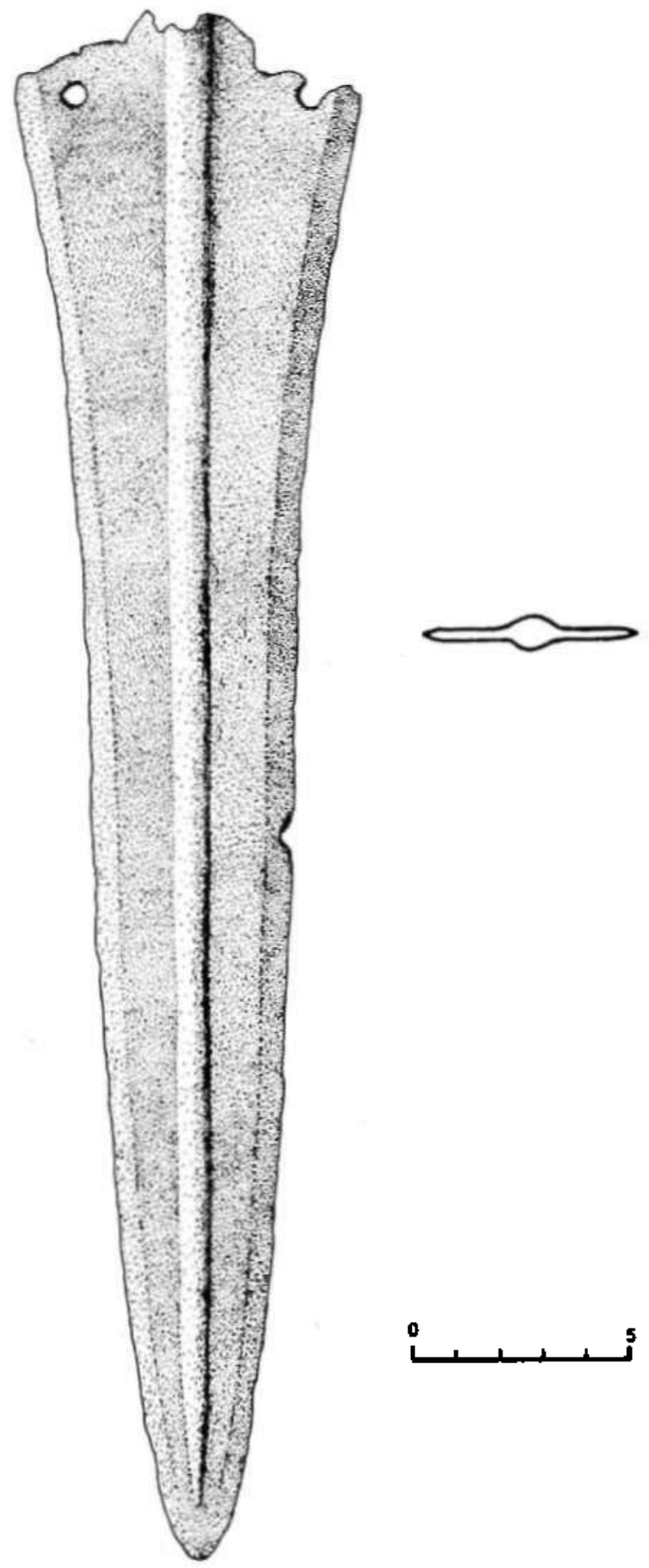

Fig. 6. Daga de Fuente Tójar.

--- Grupo de investigación P.A.I. HUM 236 | http://www.arqueocordoba.com/publ/anales.htm --- 


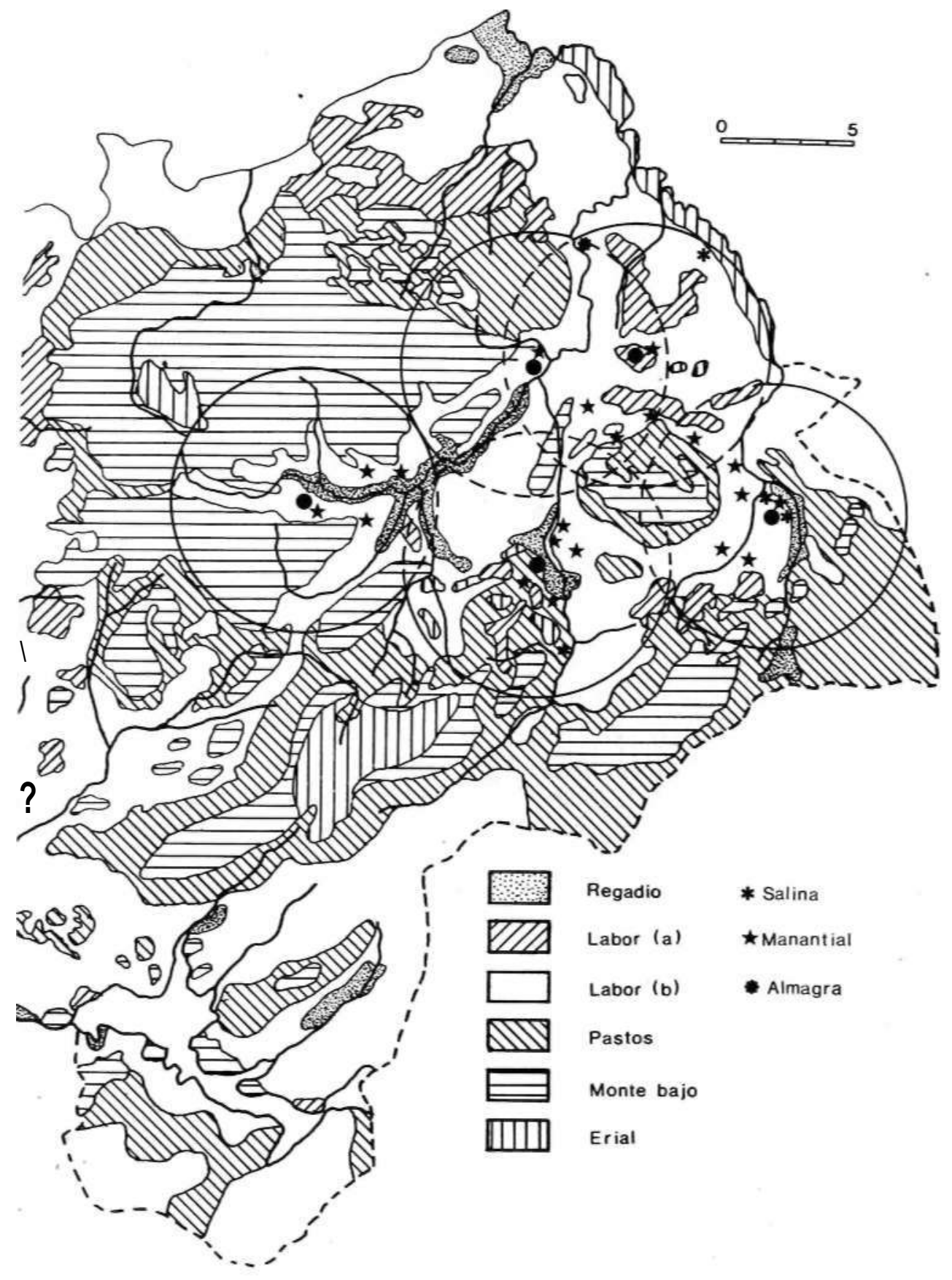

Fig. 7. Patrón de Asentamiento durante el Calcolitico y el Bronce Antiguo y Pleno. 


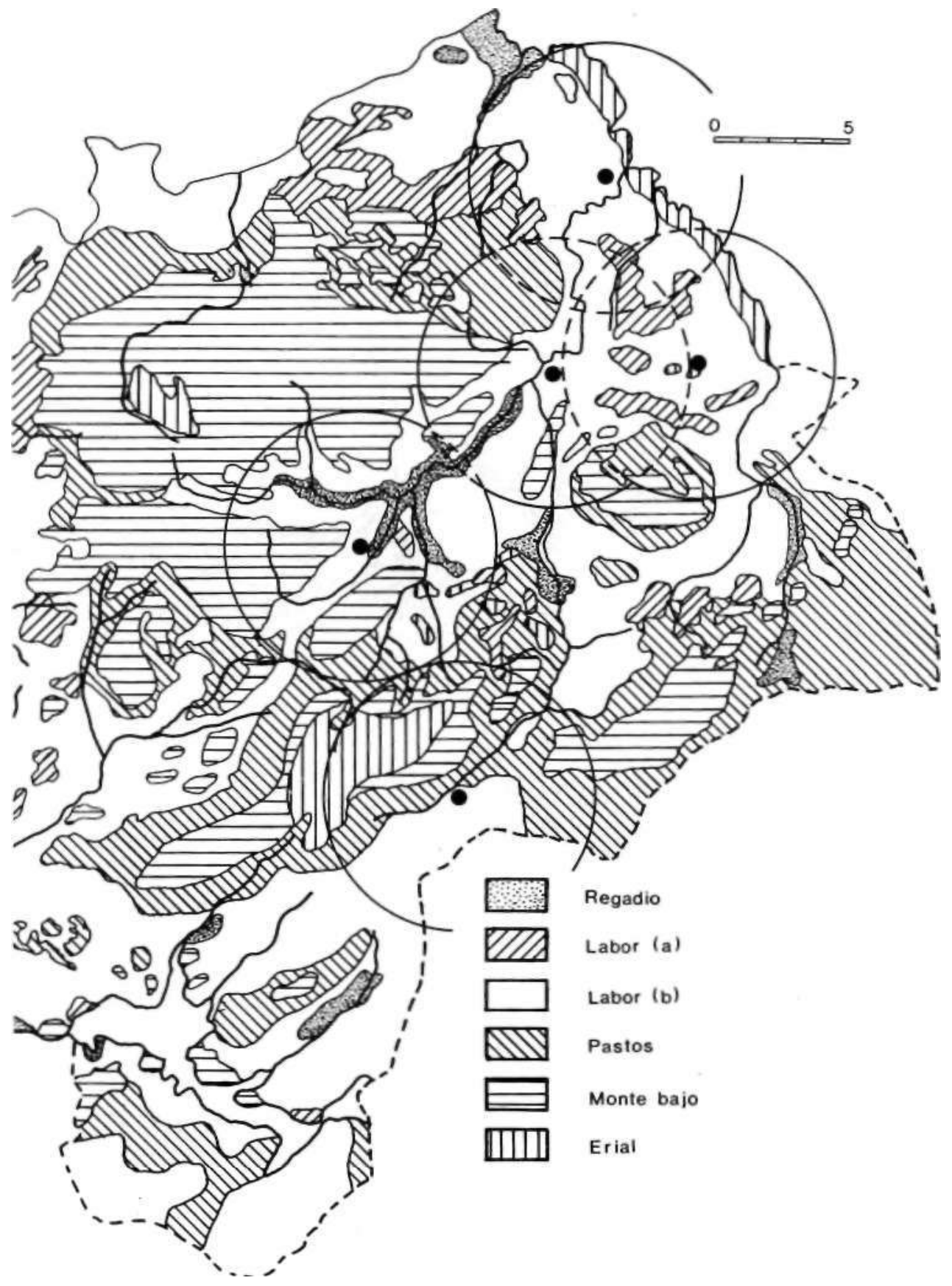

Fig. 8. Patrón de Asentamiento durante el Bronce Final-Orientalizante. 